ORIGINAL ARTICLE

\title{
An industry based approach to colorectal cancer screening in an asymptomatic population
}

\author{
A R Hart, N Glover, J Howick-Baker, J F Mayberry
}

See end of article for authors' affiliations

.....................

Correspondence to: Dr Andrew Hart, School of Medicine, Health Policy and Practice, University of East Anglia, Norwich NR4 7TJ, UK; a.hart@uea.ac.uk

Submitted

14 February 2003

Accepted 17 May 2003
The uptake of faecal occult blood testing in a workplace based colorectal cancer screening programme was investigated. Altogether 1828 employees aged 41-65 years at a large British industrial company were invited to receive a free faecal occult blood test (Haemoccult). Faecal occult blood tests were completed on three separate days. Patients with positive results were invited to undergo colonoscopy. The number of employees completing kits was measured and differences in compliance according to age, sex, and occupation were tested with a $\chi^{2}$ test. Compliance was $25.4 \%$, and similar in men $(25.0 \%)$ and women (32.0\%, $\chi^{2}=3.0$, not significant). In men, compliance was highest in those aged $51-60$ years $\left(30.5 \% \chi^{2}>11.6, p<0.001\right)$. Compliance in women aged $41-50$ years, $51-60$ years, and $61-65$ years was similar (Yates's corrected $\chi^{2}<2.08$, not significant). Managers returned more kits than clerical and blue collar workers $\left(28.6 \% \vee 23.5 \%, \chi^{2}=5.6, p<0.02\right)$. One percent of tests were positive and one patient had a tubular adenoma. Compliance in employees aged 51-60 years was comparable to that achieved in one-off British general practice programmes, but less than that in the large randomised trial of screening in general practices in Nottinghamshire. Health education of large numbers of people is easier at the workplace than in the community. Future screening must target older employees and those with clerical and blue collar jobs.
C olorectal cancer is a common cause of death from malignant disease resulting in over 19000 annual deaths in Britain ${ }^{1}$ and 57000 in the United States. ${ }^{2}$ The overall five year survival rate is only $30 \%{ }^{3}$ but for those with limited disease at presentation (Dukes's type A tumours) it is $85 \%{ }^{4}$ In the commonest method of screening, that is, faecal occult blood testing, small stool samples are analysed for microscopic traces of blood from asymptomatic cancers and polyps. Three large studies of faecal occult blood testing showed more early tumours (Dukes's A type tumours) and adenomatous polyps in the screened than control group, ${ }^{5-7}$ which lead to a reduction in mortality of $15 \%, 18 \%$, and $33 \%$ respectively.

The World Health Organisation has stated that one of the criteria necessary for a successful screening programme is a high compliance. ${ }^{8}$ A major problem in colorectal cancer screening trials is encouraging people to participate. A poor compliance means few people benefit and the economic costs are high. This problem of low compliance was identified in the Nottingham trial where only $60 \%$ of the test group completed at least one test, with just $38 \%$ returning all the follow up tests at two yearly intervals. ${ }^{5}$ Unfortunately, compliance is also a problem in other smaller community trials in British general practice, where fewer than $50 \%$ of the population participated..$^{9-15}$ An alternative approach to delivering screening, which may raise compliance, is to develop workplace based screening programmes. On-site health education at the workplace, the availability of occupational medical and nursing staff, and "word of mouth" publicity generated by discussion between employees should encourage participation and ultimately save lives.

In Britain, workplace cancer screening programmes have not been fully evaluated. This study investigated the effectiveness of such screening in a large British company. The company chosen was Brush Engineering, a heavy engineering firm in Loughborough in the East Midlands of England employing 4000 people on a single industrial site. The company manufactures railway locomotives for British
Rail and the Channel Tunnel project. If this approach succeeds then other major industries must be encouraged to develop colorectal cancer screening. Furthermore, identification of groups of employees not participating will enable specific targeting in future programmes.

\section{METHOD}

Senior managers of the Brush Group of companies in the East Midlands of England gave permission for employees aged 4165 years to receive an invitation to participate in a colorectal cancer screening project during 1992-93. The personnel departments of the engineering company sent a letter to employees explaining the purpose of bowel cancer screening and in this they were offered a free Haemoccult test pack. The scheme was advertised with posters on site and the work's medical department supported the campaign by answering inquiries. Employees who accepted were sent a Haemoccult pack which included instructions on how to perform the test. Small amounts of stool were collected and applied to cardboard slides from the kit. These were completed by employees on three separate days while on no dietary restrictions. The kits were returned to Leicester General Hospital where they were analysed by a single investigator.

A faecal occult blood test was positive if a blue colour appeared on addition of a solution of hydrogen peroxide and denatured alcohol to the stool sample. People with positive results were asked to repeat the test on dietary restrictions avoiding red meat, black pudding, cauliflower, cabbage, spinach, radishes, parsnip, broccoli, and bananas. This method reduces the number of false positives by $60 \%$ while not decreasing the initial compliance rate. ${ }^{16}$ If any of the slides tested on this second occasion was positive, employees were informed and offered colonoscopy. The length of time between the first positive result and the decision by subjects to undergo investigation was noted.

With the invitation to colonoscopy, employees received a description of the procedure and the standard bowel preparation. Before endoscopy a history was taken and 
employees underwent a complete physical examination. Employees attended as day cases on a routine list.

Individuals whose repeat tests were negative were sent a third kit to complete four months after the negative slides on dietary restrictions. Those who had a normal colonoscopy or negative repeat slides were told to contact their doctor if they later developed a change in bowel habit or related symptoms.

The number of employees who completed kits was analysed by age, sex, and occupation and tested for differences with a $\chi^{2}$ statistic. Occupations were divided into managerial and non-managerial (clerical and blue collar factory workers). The pathology found at colonoscopy was recorded.

\section{RESULTS}

\section{Compliance with screening}

Total compliance with colorectal cancer screening in this workplace scheme was $25.4 \%$ (465/1828 employees, table 1$)$. There was an additional 20.8\% (378) of people who requested a faecal occult blood kit but did not return it. Overall compliance in men was $25.0 \%(425 / 1703)$ and in women $32.0 \%(40 / 125)$, which was similar $\left(\chi^{2}=3.0\right.$, not significant (NS)). In each of the three age ranges, 41-50 years, 51-60 years, and 61-65 years there were no significant difference in completion between men and women $\left(\chi^{2}<2.2\right.$, NS). Males 51-60 years participated more $(30.5 \%)$ than men aged both $41-50$ years $\left(21.9 \%, \chi^{2}=15.1, p<0.001\right)$ and $61-65$ years $\left(16.6 \%, \chi^{2}=11.6, p<0.001\right)$. Compliance in men aged $41-50$ years and 61-65 years was similar $\left(21.9 \% v 16.6 \%, \chi^{2}=2.1\right.$, NS). Women 41 to 50 years returned kits at a similar rate to those aged $51-60$ years $\left(29.6 \% v 40.4 \%, \chi^{2}=1.5\right.$, NS $)$. There were only seven women aged 61-65 years and none of these completed a faecal occult blood test.

\section{Compliance according to occupation}

From data supplied by the company the occupations of 1803 of 1828 (98.6\%) employees were known (table 2). Of the 25 for whom occupation was unknown, 11 returned kits and this small subgroup was excluded from the analysis. Managers responded more than non-managerial employees $\left(28.6 \% \vee 23.5 \%, \chi^{2}=5.6, p<0.02\right)$. This difference was due to male managers aged $41-50$ years returning more kits than their non-managerial colleagues of the same age $(26.6 \% v$ $\left.19.6 \%, \chi^{2}=5.7, \mathrm{p}<0.02\right)$. There was no difference in compliance between male and female managers $(28.9 \% \mathrm{v}$ $20.0 \%, \chi^{2}=0.8$, NS) but female non-managers returned more kits than male non-managers $\left(35.3 \% \vee 22.4 \%, \chi^{2}=8.6\right.$, $\mathrm{p}<0.005$ ).

\section{Pathology detected}

Four of the 434 kits $(0.9 \%)$ were positive as was one on retesting with dietary restrictions. The subject with a positive test had a $1 \mathrm{~cm}$ pedunculated polyp at the splenic flexure which was removed through the colonoscope. Histology showed a tubular adenoma with mild dysplasia and complete excision margins. (The approximate financial costs of the screening in 1993 to were as follows: Haemoccult testing kits $£ 580$, staff costs $£ 5000$, colonoscopy costs £600.)

Table 1 Compliance with screening

\begin{tabular}{lll}
\hline Age (years) & Female $(\%)$ & Male $(\%)$ \\
\hline $41-50$ & $21 / 71(26.6)$ & $188 / 860(21.9)$ \\
$51-60$ & $19 / 47(40.4)$ & $213 / 698(30.5)$ \\
$61-65$ & $0 / 7(0)$ & $24 / 145(16.6)$ \\
\hline
\end{tabular}

The overall compliance for men (25.0\%) and women (32.0\%) was similar $\left(\chi^{2}=3.0, \mathrm{NS}\right)$.
Table 2 Compliance with occupation based colorectal cancer screening

\begin{tabular}{cll}
\hline Age (years) & Managerial $(\%)$ & Non-managerial $(\%)$ \\
\hline Men & & \\
$41-50$ & $76 / 286(26.6)$ & $110 / 566(19.4)$ \\
$51-60$ & $76 / 223(34.1)$ & $128 / 461(27.8)$ \\
$61-65$ & $14 / 65(21.5)$ & $10 / 80(12.5)$ \\
Women & & \\
$41-50$ & $4 / 13(30.8)$ & $17 / 56(30.3)$ \\
$51-60$ & $0 / 6(0)$ & $19 / 40(47.5)$ \\
$61-65$ & $0 / 1(0)$ & $0 / 6(0)$
\end{tabular}

Compliance in managers was higher than those with non-managerial jobs. $\left(28.6 \%\right.$ v $\left.23.5 \%, \chi^{2}=5.6, p<0.02\right)$.

\section{DISCUSSION}

Recent work proving the effectiveness of screening for colorectal cancer with faecal occult blood testing ${ }^{5-7}$ has supported the case for national screening programmes for the disease. If such programmes are to be developed, then raising compliance is going to be a major issue and ways of delivering screening such as community or workplace schemes will need to be assessed. This study found that compliance with workplace based screening was similar in men and women and higher in managers than nonmanagers. Uptake in the age group 51-60 years was similar to that in many other one-off programmes where an invitation was sent from family doctors. ${ }^{9-15}$ Therefore, workplace schemes could serve as a complementary or alternative method to community programmes for delivering screening. Encouraging participation will be easier at the workplace as medical and personnel departments can promote screening through health education publicity campaigns to large numbers of people employed at single work sites. We have previously surveyed both national and regional industries and found that businesses are interested in developing screening programmes. ${ }^{17}$ Participation was lowest in employees in their 40s and 60 s and reasons for this need to be explored. Those in their 40s may perceive themselves to be at low risk of colorectal cancer whereas workers over 60 years may feel too old to benefit from screening. Compliance in this study was considerably lower than in the large randomised controlled trial of screening in Nottinghamshire. ${ }^{5}$ This may reflect the increased public awareness of screening when it is conducted on a large scale. Furthermore, it is important to consider convenience to the investigators of delivering screening and if this is not markedly higher at the workplace it is unlikely to be practical on a large scale.

Compliance varied according to occupation with managers participating more. Managers may be more health conscious and better able to appreciate the benefits of screening and future screening programmes should particularly target clerical and blue collar workers. Although compliance according to occupation has not previously been measured in British industry, a general practice scheme found highest acceptance in those with professional occupations. ${ }^{18}$

The proportion of the total target population screened was low. Compliance may have been increased by more publicity such as promotional lectures, although the disruption to working practices prevented this. However, screening was advertised as vigorously as possible by posters displayed in factories and offices and by the medical department answering inquiries. Employees were not sent a reminder if they failed to request a kit to avoid unnecessary harassment, although a second invitation increases the response rate. ${ }^{69}$ Other studies have identified reasons for non-compliance including lack of appreciation of asymptomatic illness and screening, fear of hospital investigations and surgery, and unpleasantness of the stool collection procedure. ${ }^{18-21}$ To 
increase uptake in future programmes these reasons need to be addressed in screening invitations.

This study was necessary as there was little information on workplace colorectal cancer screening programmes in British industry. In one previous study workers over 40 years of age in two companies were invited to receive a Haemoccult kit and complete a symptom questionnaire. ${ }^{22}$ Although overall compliance was $51 \%$ with women participating significantly more than men $(61 \% \vee 47 \%)$, uptake according to age and occupation were not reported. The intense publicity with lectures, leaflets, and small group discussion may have encouraged greater participation than in our study. In America workplace screening has been more extensively investigated. After the discovery of an excess number of colonic cancers at a Texan polypropylene factory, ${ }^{23}$ past and present employees over 40 years of age were offered a faecal occult blood test and flexible sigmoidoscopy. ${ }^{24}$ Overall participation was 52\%, although among current employees it was $68 \%$. Those most likely to participate were aged 50-59 years and those least likely older than 60 years. Attendance at a promotional briefing was associated with an increased level of participation. Pattern and model makers in the Detroit car industry are also at a high risk and were screened. ${ }^{25}$ The uptake by a group of workers at one year was $46 \%$, although this fell to $16 \%$ five years later. Reasons for non-participation included a failure to understand the benefits of screening and concern regarding the sigmoidoscopy. The American Pennzoil Company offered faecal occult blood tests and flexible sigmoidoscopy to employees over 40 years of age and with a family history of colonic carcinoma. ${ }^{26}$ Compliance was $20 \%$ with faecal occult blood testing and 31\% with sigmoidoscopy. In a general cancer prevention programme in textile workers in North Carolina, 68\% of employees agreed to be screened for one or more of six different cancers. ${ }^{27}$ In a survey of 358 businesses in Colorado 468 companies with more than 50 employees were questioned and a quarter were found to offer a colorectal cancer screening service. ${ }^{28}$ A similar survey of 424 Californian companies found $8 \%$ offered a "cancer risk reduction" programme, although its precise nature and whether bowel cancer screening was offered was not reported..$^{29}$ In a survey of industries in the East Midlands of England we reported that a quarter of businesses would advertise screening and run such a service in liaison with their local hospital. ${ }^{17}$ Many companies rejected screening because they thought the workforce would be disinterested, although data do not support this view. ${ }^{22} 24$

The pathology detection rate in this trial of one person with a polyp among 250 screened in the 51-60 age group was similar to that in other work. ${ }^{6}$ However, many people aged 41-50 years were screened with no pathology detected. Offering screening to this age group is probably only justifiable to those with a family history of colorectal cancer who are at increased risk of the disease.

Colorectal cancer screening with faecal occult blood testing has been shown to reduce mortality by $15 \%$ in Britain, ${ }^{5} 18 \%$ in Denmark, ${ }^{6}$ and by $33 \%$ in America. ${ }^{7}$ The greater success rate from the United States may have been due to the five times higher number of positive tests for occult blood than in the European studies, due to the American practice of rehydrating test slides. This lead to a higher colonoscopy rate with the detection of more cancers and pre-malignant adenomas.

Screening for colorectal cancer with faecal occult blood testing reduces mortality, but ways to increase compliance are needed. Compliance and effectiveness also needs to be compared with other screening modalities which are being developed such as flexible sigmoidoscopy. ${ }^{30}$ Workplace schemes could be developed as they may offer opportunities to educate large number of people about the benefits of screening at a single site. All groups of people need to be encouraged to participate but especially older employees and those with non-managerial occupations. Reasons for noncompliance need to be addressed in such programmes such as lack of awareness of the concept of asymptomatic illness and the frequency of colorectal cancer, unpleasantness of the stool collection procedure, and fear of further investigations and surgery. ${ }^{182}$ If companies support and finance screening the health and financial benefits to individuals, businesses and the country would be enormous.

\section{ACKNOWLEDGEMENTS}

We would like to thank the Chairman, Managing Director, Personnel Departments and the Medical Centre at the Brush Group of Companies, Loughborough, for their help with administering the project.

\section{Authors' affiliations}

A R Hart, N Glover, J F Mayberry, Gastroenterology Research Unit, Leicester General Hospital, Leicester

J Howick-Baker, Brush Industries Limited, Loughborough, Leicestershire

\section{REFERENCES}

1 Office of Population Censuses and Surveys. Mortality statistics 1990. Series $\mathrm{CH}$ 2, 17. London: H M Stationery Office, 1991.

2 Boring CC, Squire TS, Tong T. Cancer statistics. CA Cancer J Clin 1993;43:7-26.

3 Gill PG, Morris PJ. The survival of patients with colorectal cancer treated in regional hospital. Br J Surg 1978;65:17-20.

4 Halliday $\mathbf{H}$, Hardcastle JD. Delay in diagnosis and treatment of symptomatic colorectal cancer. Lancet 1979;i:309-11.

5 Hardcastle JD, Chamberlain J, Robinson NHE, et al. Randomised controlled trial of faecal occult blood screening for colorectal cancer. Lancet 1996:348:1467-71.

6 Kronborg O, Fenberg C, Olsen J, et al. Randomised study of screening for colorectal cancer with faecal occult blood. Lancet 1996;348:1467-71.

7 Mandel JS, Bond JH, Church TR, et al. Reducing mortality form colorectal cancer by screening for faecal occult blood. N Engl J Med 1993;328:1365-71.

8 World Health Organisation. Principles and practice of screening for disease. In: Wilson JMG, Jungner G, eds. Public health papers 34. Geneva: WHO, 1968.

9 Lallemand RC, Vakil PA, Person P, et al. Screening for asymptomatic bowel cancer in general practice. BMJ 1984;288:31-3.

10 Mant D, Chivers A, Fuller A, et al. Patient compliance with colorectal cancer screening in general practice. Br J Gen Pract 1992;42:18-20.

11 Farrands PA, Griffiths RL, Britton DC. The Frome Experiment-value of screening for colorectal cancer. Lancet $1981 ; \mathrm{i}: 1231-2$.

12 Hart AR, Gay SP, Donnelly A, et al. Screening for colorectal cancer in Market Harborough UK. A community based programme. Eur J Gastroenterol Hepatol 1994;6:519-22.

13 Hobbs FDR, Cherry RC, Fielding JWL, et al. Acceptability of opportunistic screening for occult gastrointestinal blood loss. BMJ 1992;304:483-6.

14 Nichols S, Koch E, Lallemand RC, et al. Randomised trial of compliance with screening for colorectal cancer. BMJ 1986;293:107-10.

15 Million R, Howart J, Turnberg E, et al. Faecal occult blood testing for colorectal cancer in general practice. The Practitioner 1982;226:659-61.

16 Thomas WM, Pye G, Hardcastle JD, et al. Role of dietary restriction in Haemoccult screening for colorectal cancer. Br J Surg 1986;76:976-8.

17 Hart AR, Wicks ACB, Mayberry JF. A survey of industries and colorectal cancer screening of employees in the East Midlands of England. J R Soc Med 1993;86:571-2.

18 Farrands PA, Hardcastle JD, Chamberlain J, et al. Factors affecting compliance with screening for colorectal cancer. Community Medicine 1984:6:12-19.

19 Spector MH, Applegate WB, Olmstead SJ, et al. Assessment of attitudes towards mass screening for colorectal cancer and polyps. Prev Med 1981;10:105-9

20 Silman PA, Mitchell P. Attitudes of non-participants in an occupational based programme of screening for colorectal cancer. Community Medicine 1984;6:8-11.

21 Hynam KA, Hart AR, Gay SP, et al. Screening for colorectal cancer: reasons for refusal of faecal occult blood testing in a general practice in England. $J$ Epidemiol Community Health 1995:49:84-6.

22 Silman PA, Mitchell P, Nicholls RJ, et al. Self-reported dark red bleeding as a marker comparable with occult blood testing in screening for large bowel neoplasms. Br J Surg 1983;70:721-4.

23 Acquavella JF, Douglass TS, Phillips SC. Evaluation of excess colorectal cancer incidence among workers involved in the manufacture of polypropylene. J Occup Med 1988;30:438-41.

24 Vernon SW, Acquavella JF, Douglass TS, et al. Factors associated with participation in an occupational programme for colorectal cancer screening. J Occup Med 1989;5:458-63. 
25 Neale AV Demers RY Herman S. Compliance with colorectal cancer screening in a high risk occupational group. J Occup Med 1989; 12:1007-12. 26 Laville EA, Vernon SW, Jackson GL, et al. Comparison of participants and non-participants in a worksite cancer awareness and screening programme. J Occup Med 1989:31:221-31.

27 Heyden S, Fodor JG. Industrial cancer education and screening for 19,000 Cannon Mills employees. J Chronic Dis 1981;34:225-31.
28 Davis MF, Rosenberg K, lverson DC, et al. Worksite health promotion in Colorado. Public Health Rep 1984;6:538-543.

29 Fielding JE, Breslow L. Health promotion programs sponsored by California employers. Am J Public Health 1983;73:538-42.

30 UK Flexible Sigmoidoscopy Screening Trial Investigators. Single flexible sigmoidoscopy screening to prevent colorectal cancer: baseline findings of a UK multicentre randomised trial. Lancet 2002;359:1266-7.

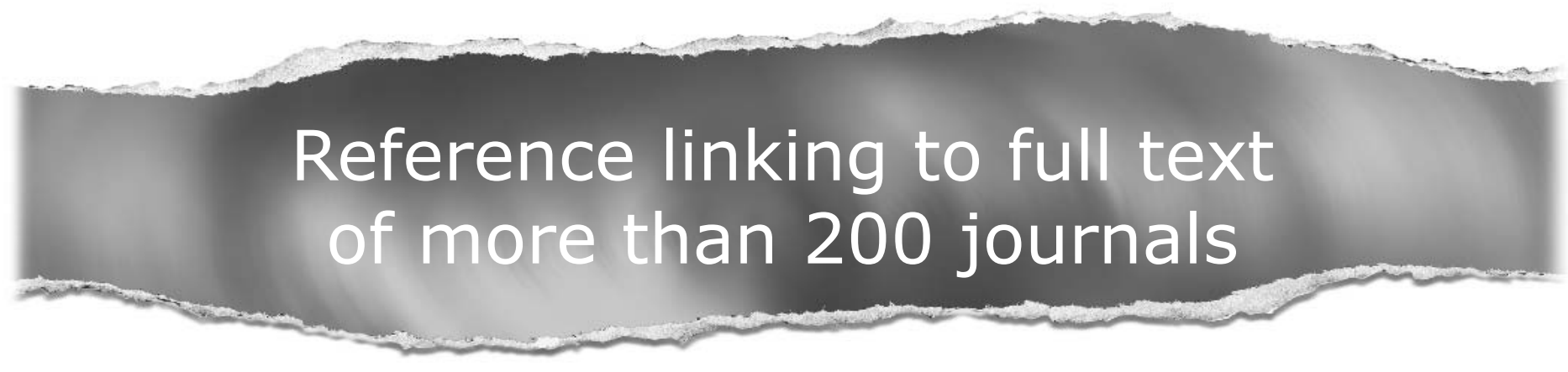

\section{Toll free links}

You can access the FULL TEXT of articles cited in Postgraduate Medical Journal online if the citation is to one of the more than 200 journals hosted by HighWire (http://highwire.stanford.edu) without a subscription to that journal. There are also direct links from references to the Medline abstract for other titles.

www.postgradmedj.com 